
\title{
CIÊNCIANATURA
}

\section{Proposta de utilização de sistema híbrido eólico/solar de geração de energia em estabelecimentos comerciais na Ilha do Mel-PR}

\author{
Jackson Milano
}

Universidade Positivo

\begin{abstract}
Resumo
O presente trabalho refere-se a uma proposta de utilização de um sistema híbrido eólico/solar de geração de energia distribuída, em estabelecimentos na Ilha do Mel, no estado do Paraná no sul do Brasil. Acessibilidade, questões ambientais e variabilidade populacional foram levadas em consideração, pois influenciaram nos cálculos do projeto executado. Os dados climáticos (radiação solar, temperatura, velocidade do vento) para modelagem do sistema foram obtidos do software RETScreen; o levantamento dos custos para aquisição e instalação dos sistemas eólico e solar foi realizado através de uma pesquisa de mercado; e as curvas de carga dos estabelecimentos alvo da pesquisa foram geradas a partir da coleta de dados em campo, com um medidor e registrador de grandezas em tempo real para sistemas elétricos. As informações brutas foram tratadas no Excel e a modelagem, simulação e análise de sensibilidade dos sistemas híbridos foram executadas no software HOMER. Os resultados evidenciaram configurações de sistemas híbridos possivveis tanto técnica como economicamente, apesar de sugerir que em estabelecimentos de menor demanda energética, a instalação de sistemas eólicos se mostra menos viável devido ao alto custo de aquisição, instalação e reposição das turbinas, enquanto que os sistemas solares se revelam sempre viáveis.
\end{abstract}

Palavras-chave: Geração distribuida; Sistema híbrido eólico/solar; Região litorânea isolada

\section{Abstract}

This paper presents a proposal for the utilization of a hybrid wind/solar system for generating distributed energy in establishments in Ilha do Mel, in the state of Paraná, in the southern of Brazil. Accessibility, environmental issues and population variability were taken into account, as they influenced the project calculations performed. The climatic data (solar radiation, temperature, wind speed) required for modeling the system were obtained by extracting information from the RETScreen software; the survey about the costs for the acquisition and installation of the wind and solar systems was carried out through a market research; and the load curves of the researched establishments were generated from data collected from the field, using a real-time meter and recorder of quantities for electrical systems. The raw information was treated in Excel and the modeling, simulation and sensitivity analysis of the hybrid system were performed by the HOMER software. The results showed possible configurations of hybrid systems both technically and economically, although the results suggest that in facilities with a lower energy demand, the installation of wind systems is less feasible due to the high cost of acquisition, installation and replacement of the turbines, while solar systems turn out to be always viable.

Keywords: Distributed generation; Wind / solar hybrid system; Isolated coastal region 


\section{Introdução}

As fontes de energia classificadas como renováveis, costumeiramente estão ligadas ao conceito de energia limpa, pois se comparadas com fontes tradicionais como petróleo, gás e carvão, praticamente não geram resíduos ou emissão de poluentes além de seus impactos ambientais serem muito baixos. Entende-se por fontes renováveis de energia aquelas consideradas inesgotáveis para os padrões humanos de utilização (VILLALVA, 2015), a energia solar, eólica, hidrelétrica, das marés, geotérmica e da biomassa são alguns exemplos.

O aumento na produção desse tipo de fonte, especificamente no Brasil, foi modesto até o ano de 2017, uma vez que a matriz energética brasileira está baseada na geração de energia por usinas hidrelétricas e termelétricas, que juntas, foram responsáveis, no ano de 2016, por $88,4 \%$ de toda a capacidade instalada no país, passando a 90,31\% no ano de 2017 , como ilustra a Tabela 1, obtida do Balanço Energético Nacional de 2018. Com os parques eólicos instalados nos últimos anos, principalmente na região nordeste, houve um crescimento dessa fonte, passando de 1.894 MW em 2012 para 12.283 MW em 2017, representando mais de 648\% de aumento, mas ainda com uma participação final de apenas 7,8\% de toda a capacidade instalada no Brasil naquele ano. Em contrapartida, a energia solar, não apresentou o mesmo desempenho e sua participação percentual no cenário nacional, até o ano de 2016 foi praticamente nula. Entre 2016 e 2017, a produção de energia solar apresentou o extraordinário percentual de $3.836 \%$ de aumento, mas a produção solar representou apenas $5,46 \%$ de toda a capacidade instalada em 2017.

Tabela 1 - Capacidade instalada de geração elétrica no Brasil (MW)

\begin{tabular}{c|c|c|c|c|c|c|c}
\hline & 2012 & 2013 & 2014 & 2015 & 2016 & 2017 & $\begin{array}{c}\Delta \% \\
(2017 / 2016)\end{array}$ \\
\hline Hidrelétricas & 79.956 & 81.132 & 84.095 & 86.366 & 96.925 & 100.275 & 3,5 \\
\hline Termelétricas & 32.778 & 36.528 & 37.827 & 39.564 & 41.275 & 41.628 & 0,9 \\
\hline Nucleares & 2.007 & 1.990 & 1.990 & 1.990 & 1.990 & 1.990 & 0,0 \\
\hline Eólicas & 1.894 & 2.202 & 4.888 & 7.633 & 10.124 & 12.283 & 21,3 \\
\hline Solar & 2 & 5 & 15 & 21 & 24 & 935 & 3836 \\
\hline Total & 120.975 & 126.743 & 133.913 & 140.858 & 150.338 & 157.112 & 4,5 \\
\hline
\end{tabular}

Mas a intenção é mudar esse cenário no Brasil, como mostra o Plano Decenal de Expansão de Energia - PDE 2024, editado em dezembro de 2015, elaborado pela Secretaria de Planejamento e Desenvolvimento do Ministério das Minas e Energias juntamente com a Empresa de Pesquisa Energética (EPE) e o Governo Federal Brasileiro, onde se estabelece como meta, que as energias renováveis devem representar aproximadamente $86 \%$ de toda geração de energia em 2024. Com as projeções de crescimento econômico do país e a necessária expansão da oferta, de forma a garantir à sociedade o suprimento energético com adequados custos, em bases técnica e ambientalmente sustentável, o relatório prevê um processo de diversificação da matriz de energia elétrica (EPE, 2015b).

Com incentivos governamentais como linhas de crédito bancário para projetos com utilização de energias renováveis, isenção parcial ou total de impostos de importação dos equipamentos destinados a estes projetos e normas técnicas/regulamentações condizentes com a realidade brasileira, o setor privado brasileiro poderá sair da posição de apenas consumidor para se tornar também gerador de energia elétrica. Até mesmo pessoas físicas podem ter em suas residências geradores eólicos de pequeno porte e painéis solares fotovoltaicos a fím de produzirem sua própria energia. Segundo afirma 
Costa (2014), uma das alternativas ao atual cenário é distribuir a geração de energia com potências instaladas menores, próximas aos centros de carga, diminuindo assim, os custos elevados com transmissão e o elevado impacto ambiental da geração de grande porte.

As fontes alternativas solar e eólica são as de maior potencial para utilização na geração distribuída que se caracteriza pelo uso de geradores próximos ao local de consumo, sem a necessidade de linhas de transmissão e conectadas diretamente às redes de distribuição de baixa tensão da concessionária de energia local. Atualmente no Brasil, as normas em vigor permitem a microgeração e a minigeração de energia que além de servir ao consumo próprio, pode ser usada para gerar créditos de energia no sistema de compensação nos períodos em que a geração é maior que o consumo, esta Resolução Normativa foi editada em abril de 2012 pela Agência Nacional de Energia Elétrica (ANEEL), sob o n ${ }^{0} 482$.

Como consequência da Normativa $\mathrm{n}^{\circ} 482$, houve um aumento no número de conexões de sistemas de micro e minigeração no Brasil desde o mês de dezembro de 2012, com apenas uma conexão para 10.561 ligações em maio de 2017, conforme ilustra a Figura 1 que consta da Nota Técnica 0065/2017 da ANEEL.

Figura 1 - Evolução do número de conexões e consumidores com crédito de micro e minigeração até maio/17

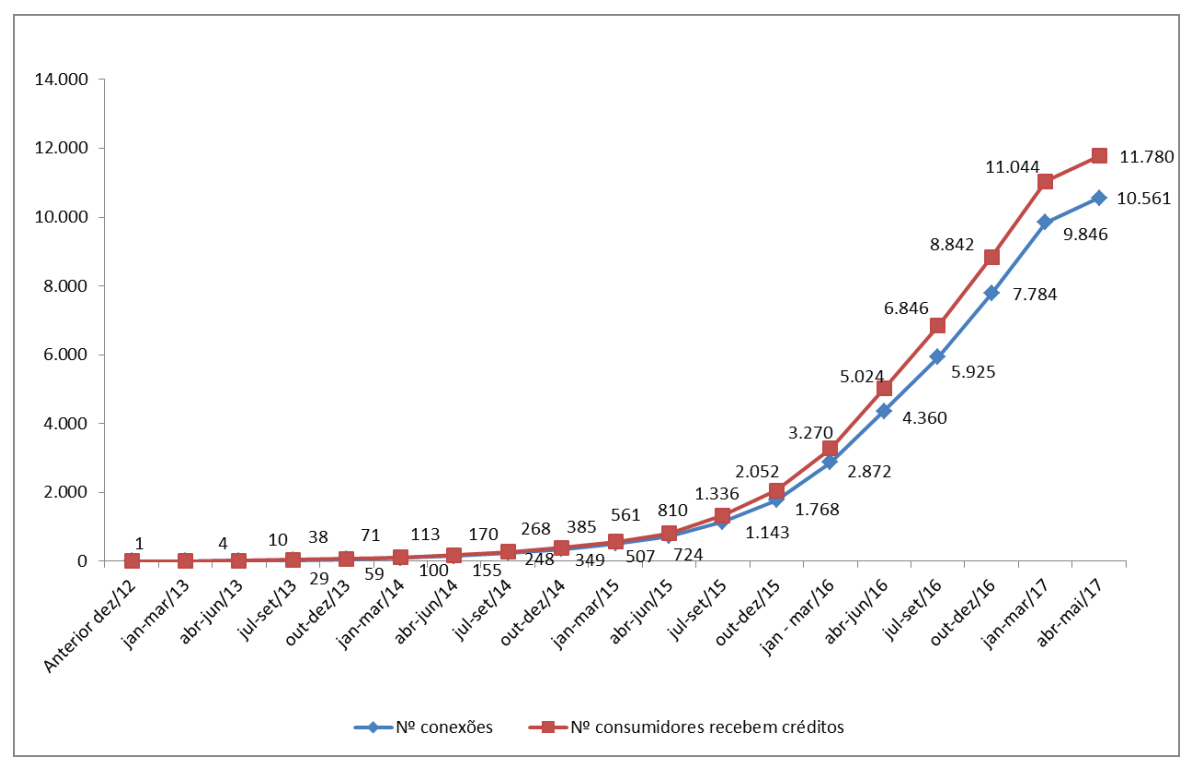

Segundo a Nota Técnica 0065/2017, do total de 10.561 conexões de micro e minigeração distribuída, 10.453 são de sistemas fotovoltaicos, 50 de sistemas eólicos, 40 utilizando como fonte de energia o biogás, 12 a energia hídrica e 5 a biomassa. Com relação à participação dos consumidores, a ANEEL destaca as classes residencial (79,5\%) e a comercial $(15 \%)$.

Com base na legislação favorável a micro e minigeração de energia e considerando os benefícios ecológicos da produção de energias renováveis, o estado do Paraná está apto a explorar tais fontes mais intensamente em todo seu território. Uma região que pode se beneficiar diretamente deste recurso é o litoral do estado composto por várias ilhas, como é o caso da Ilha do Mel, inserida em uma estação ecológica e em um parque estadual.

Como inexistem fontes de energia na ilha, toda a necessidade elétrica depende de um cabo submarino de $6,2 \mathrm{~km}$ de extensão que transporta a energia de uma subestação em Pontal do Paraná, situada no continente, até a ilha. 
Considerando as condições geográficas e climáticas da Ilha do Mel, o presente trabalho propõe a utilização de sistemas híbridos de geração eólica/solar nos estabelecimentos comerciais ali localizados.

O objetivo geral deste trabalho consiste em investigar a possibilidade de aproveitamento do potencial energético, em região litorânea remota para utilização de energia limpa e renovável como uma fonte confiável e constante para auxiliar na alimentação dos estabelecimentos comerciais. Está organizado com uma apresentação dos materiais e da metodologia utilizados, uma descrição do estudo de caso, dos dados levantados para efetuar a modelagem dos sistemas de geração distribuída, as simulações e otimizações realizadas no software HOMER e as conclusões finais obtidas.

\section{Materiais}

Para simular sistemas de geração distribuída com vários tipos de fontes renováveis, fez-se necessária a utilização de recursos computacionais específicos com o objetivo de gerar confiabilidade nos resultados obtidos. Para isso, neste trabalho foram utilizados os softwares RETScreen Expert e HOMER que serão apresentados na sequência. Além dos softwares também foi utilizado o analisador de energia MARH 21 para obtenção dos dados de consumo dos estabelecimentos comerciais com o objetivo de construir a curva de carga.

O software RETScreen Expert desenvolvido pelo Natural Resource Canada's é uma ferramenta especificamente destinada a facilitar a análise e viabilidade de tecnologias de energia limpa. A ferramenta possui um banco de dados integrado de produtos, de comparação, de custos, de informações climáticas e meteorológicas. Os dados dos produtos presentes são fornecidos por fabricantes comerciais de equipamentos, enquanto os dados meteorológicos, de mais de 1.000 localidades do mundo, são extraídos de estações de medição terrestres ou de satélites obtidos pela NASA derivados de uma série histórica de mais de 30 anos. Dentre esses dados meteorológicos estão as médias mensais da temperatura do ar e do solo, umidade relativa do ar, precipitação, radiação solar diária horizontal, pressão atmosférica e velocidade do vento.

O software HOMER foi desenvolvido no National Renewable Energy Laboratory (NREL) nos Estados Unidos da América e pode simular sistemas isolados ou conectados à rede, combinados com diferentes tipos de geração, como eólica, solar, biogás, células a combustíveis, geradores a diesel, etc. O HOMER possui descrições de modelos simplificados dos sistemas, realiza cálculos em base de tempo horária para centenas de configurações de sistemas, apresentando-os de acordo com o seu custo total de instalação e operação ao longo da vida útil, além de permitir a otimização de parâmetros técnicos específicos de cada configuração do sistema. O software solicita a inclusão de valores médios mensais de irradiância e velocidade do vento com os quais gera sinteticamente dados horários.

Resumidamente, o HOMER realiza três tarefas principais, que são: simulação, otimização e análise de sensibilidade. Uma única otimização consiste em múltiplas simulações, da mesma forma que uma única análise de sensibilidade consiste em otimizações múltiplas. Na etapa da simulação, o HOMER modela o desempenho de uma configuração de um sistema de microgeração a cada hora do ano para determinar sua viabilidade técnica e custo do ciclo de vida. No processo de otimização é realizada a simulação de muitas configurações de sistemas diferentes em busca daquela que satisfaz as restrições técnicas ao menor custo do ciclo de vida, determinando o "valor ótimo" das variáveis sobre as quais se tem controle como a combinação de componentes que compõem o sistema, tamanho e potência de cada um. No processo de sensibilidade, o software realiza otimizações múltiplas sob uma gama de suposições de entrada a fim de avaliar os efeitos da incerteza ou mudanças na entrada do modelo. Essa análise de sensibilidade ajuda a avaliar as variáveis que não se tem controle, como irradiação solar, velocidade média do vento ou preço futuro do combustível. 
O MARH-21 é um medidor e registrador de grandezas em tempo real para sistemas elétricos em baixa, média e alta tensão, fabricado pela RMS Sistemas Eletrônicos. Sua alimentação pode ser feita diretamente pela entrada de sinal de tensão, pela entrada auxiliar em tensão alternada de 70 a 600 VCA ou por uma entrada de tensão contínua de 11 a 60 VCC. Com as informações dos sinais de entrada, o medidor é capaz de indicar no mostrador digital os valores de tensão, corrente, potência, energia, temperatura e pressão, entre outras. Os dados medidos são armazenados na memória de massa do registrador e podem, posteriormente, ser transferidos para qualquer computador e analisados na forma de gráficos e relatórios por meio do software ANAWIN. Tais gráficos e relatórios podem relacionar os valores medidos e registrados com o horário em que ocorreram e desta forma, possibilitar a análise do comportamento das diversas variáveis no período de medição.

\section{Metodologia}

Como o objetivo do presente trabalho é propor a utilização de fontes renováveis de energia como alternativa em estabelecimentos comerciais em uma ilha, a metodologia adotada é diferente quando comparada a instalações similares em meio rural ou urbano. Informações como acessibilidade, questões ambientais e variabilidade populacional devem ser levadas em consideração, pois são relevantes para o cálculo do projeto a ser executado de modo a atender as necessidades específicas do local. A Figura 2 ilustra um fluxograma resumido da metodologia proposta para a realização deste trabalho.

\section{Figura 2 - Fluxograma da metodologia}

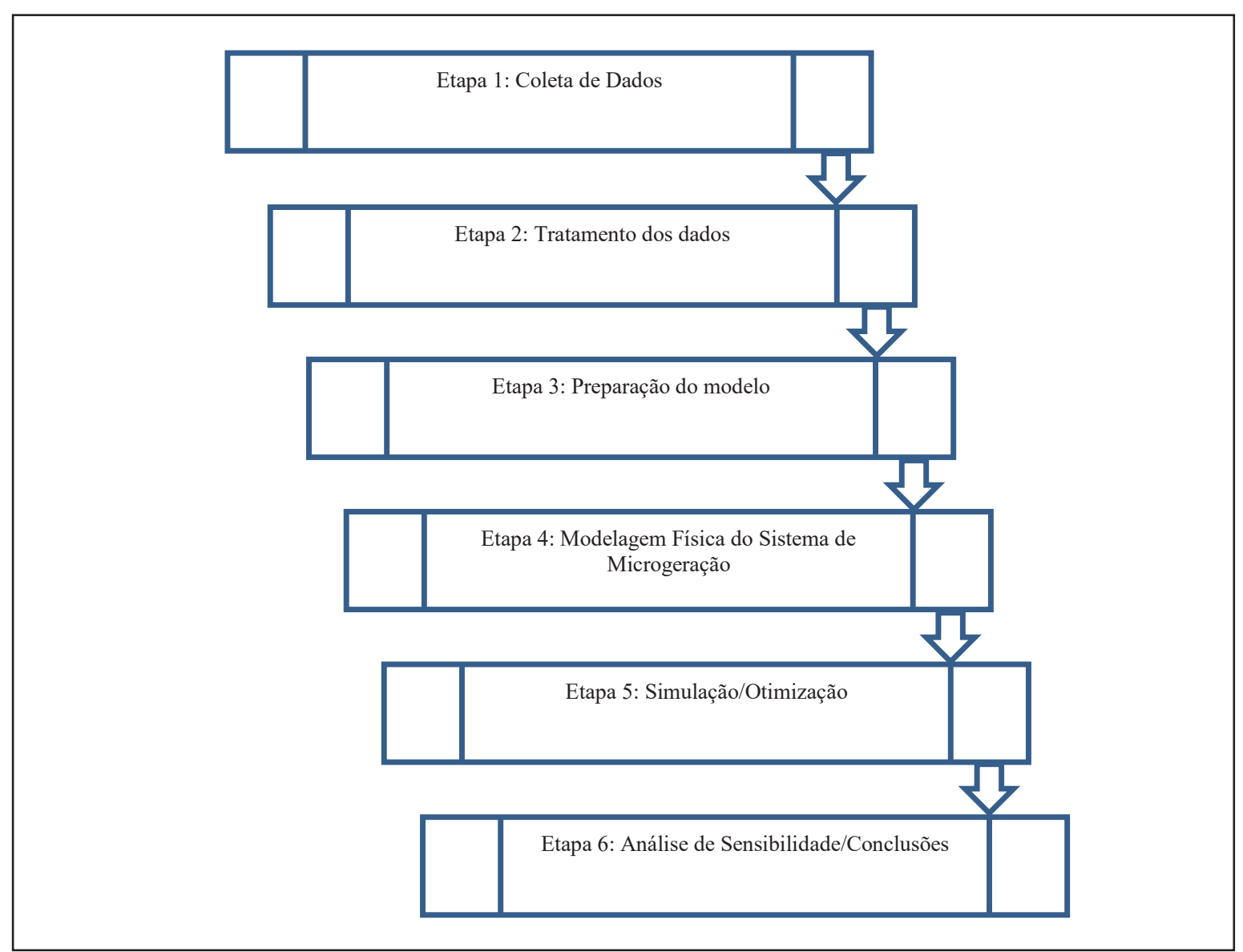




\section{Estudo de caso}

Este tópico apresenta uma aplicação da metodologia proposta, considerando como local de estudo duas pousadas na Ilha do Mel - Paraná. Também expõe a descrição do local, os dados físicos dos estabelecimentos comerciais/pousadas escolhidas para o estudo de caso, assim como os dados climáticos da região, os dados para levantamento da curva de carga das pousadas, a pesquisa de mercado sobre os equipamentos do sistema, a modelagem, simulação e otimização destas informações no software HOMER.

\subsection{A Ilha do Mel}

Pertencente ao município de Paranaguá, a Ilha do Mel, situada no litoral do estado do Paraná possui aproximadamente $95 \%$ de sua área composta por restinga e floresta de mata atlântica. Possui uma área total de 27,62 km² sendo que a maior parte está dentro de uma Estação Ecológica $\left(22,4 \mathrm{~km}^{2}\right)$, situada ao norte ou no Parque Estadual da Ilha do $\operatorname{Mel}\left(3,3 \mathrm{~km}^{2}\right)$, situado ao sul. Menos de $2 \mathrm{~km}^{2}$ têm permissão de uso residencial ou comercial. Como não existem estradas ou ruas na ilha, a locomoção entre os cinco vilarejos, Fortaleza, Nova Brasília, Farol, Praia Grande e Encantadas é feita a pé ou de bicicleta. A área total de praias na ilha chega a $0,55 \mathrm{~km}^{2}$ e a altitude máxima é de 151 metros.

Dentre todas as alternativas existentes para obtenção dos principais dados climáticos necessários para abastecer o software de simulação HOMER foi utilizada a ferramenta RETscreen, e a estação localizada na cidade de Paranaguá, distante apenas $21 \mathrm{~km}$ do local da instalação, com exatamente a mesma latitude sul $\left(-25,5^{\circ}\right)$ e praticamente a mesma longitude, com diferença de apenas $0,2^{\circ}$, o que tornou perfeitamente possível a utilização dos dados dessa estação. A Tabela 2 ilustra as médias mensais fornecidas pelo software de alguns dados climáticos utilizados para a modelagem dos sistemas.

Tabela 2 - Dados climáticos

\begin{tabular}{|c|c|c|c|c|c|}
\hline Mês & $\begin{array}{c}\text { Temperatura } \\
\text { do ar } \\
\left({ }^{\circ} \mathrm{C}\right)\end{array}$ & $\begin{array}{c}\text { Radiação solar } \\
\text { diária horizontal } \\
\left(\mathrm{KWh} / \mathrm{m}^{2} / \mathrm{dia}\right)\end{array}$ & $\begin{array}{c}\text { Pressão } \\
\text { Atmosférica } \\
(\mathrm{KPa})\end{array}$ & $\begin{array}{l}\text { Velocidade do } \\
\text { vento } \\
(\mathrm{m} / \mathrm{s})\end{array}$ & $\begin{array}{c}\text { Temperatura } \\
\text { do solo } \\
\left({ }^{\circ} \mathrm{C}\right)\end{array}$ \\
\hline Janeiro & 23,7 & 4,99 & 97,0 & 3,3 & 24,3 \\
\hline Fevereiro & 23,8 & 4,72 & 97,2 & 3,2 & 24,3 \\
\hline Março & 23,1 & 4,27 & 97,2 & 3,3 & 23,4 \\
\hline Abril & 21,7 & 3,62 & 97,4 & 3,2 & 21,7 \\
\hline Maio & 19,2 & 3,07 & 97,6 & 3,3 & 18,8 \\
\hline Junho & 17,5 & 2,83 & 97,7 & 3,4 & 16,9 \\
\hline Julho & 17,5 & 3,01 & 97,8 & 3,4 & 16,9 \\
\hline Agosto & 18,2 & 3,65 & 97,8 & 3,6 & 18,2 \\
\hline Setembro & 18,7 & 3,53 & 97,6 & 3,9 & 19,3 \\
\hline Outubro & 20,2 & 4,22 & 97,4 & 3,8 & 21,1 \\
\hline Novembro & 21,6 & 5,02 & 97,2 & 3,8 & 22,6 \\
\hline Dezembro & 23,0 & 5,15 & 97,0 & 3,7 & 23,9 \\
\hline Anual & 20,7 & 4,00 & 97,4 & 3,5 & 21,0 \\
\hline Medido a & & & & $10 \mathrm{~m}$ & $0 \mathrm{~m}$ \\
\hline
\end{tabular}




\subsection{As pousadas}

A Pousada A, localizada em Nova Brasília na Ilha do Mel, possui 10 apartamentos, totalizando 20 leitos para hóspedes, todos com banheiro privativo, ar condicionado, frigobar, chuveiro elétrico e TV LCD. A construção está dividida em dois ambientes sendo que apenas o maior, com telhado dividido em duas águas, possui possibilidade de instalação dos painéis fotovoltaicos. A Figura 3 ilustra um dos telhados possíveis de utilização na pousada A.

Figura 3 - Telhado da pousada A com potencial fotovoltaico

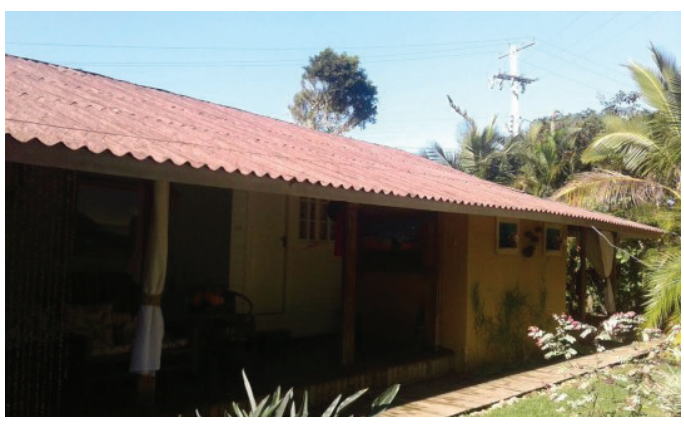

O consumo médio da Pousada A, entre os meses de dezembro de 2015 e novembro de 2016 foi de 1195,75 kWh, com os maiores valores concentrados nos meses de janeiro (2782 kWh) e fevereiro (2778 kWh) e os menores nos meses de agosto (489 kWh) e setembro (599 kWh). Concluída a realização das medições das grandezas elétricas com a utilização do equipamento MARH-21 instalado entre os dias 15/02/17 e 08/03/17 na Pousada A e após o tratamento dos dados brutos com o software Excel, foi possível obter os valores da potência $(\mathrm{kW})$ para cada hora do dia para todo o período monitorado. A Figura 4 ilustra a curva de carga da Pousada A para três dias distintos, de baixa (23/fev), média (16/fev) e alta ocupação $(27 / \mathrm{fev})$.

Figura 4 - Curva de carga para três dias da pousada A

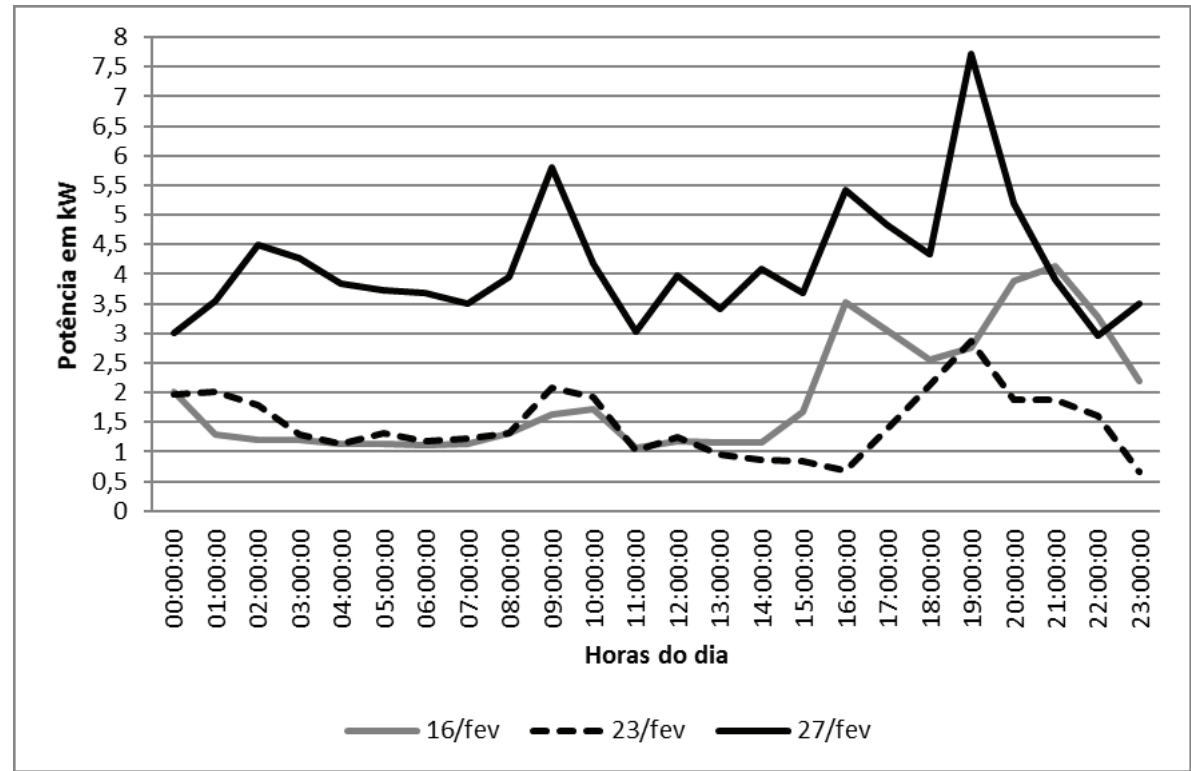


Em virtude do tipo de estabelecimento comercial analisado, existem diferenças significativas na curva de carga em dias muito próximos dentro do mesmo mês. Com os dados levantados, foi construído um gráfico representando a potência média por dia para todo o período de monitoramento na Pousada A. A Figura 5 demonstra a potência média (kW) por dia entre os dias 15/02/2017 e 08/04/2017.

Figura 5 - Potência média diária da pousada A

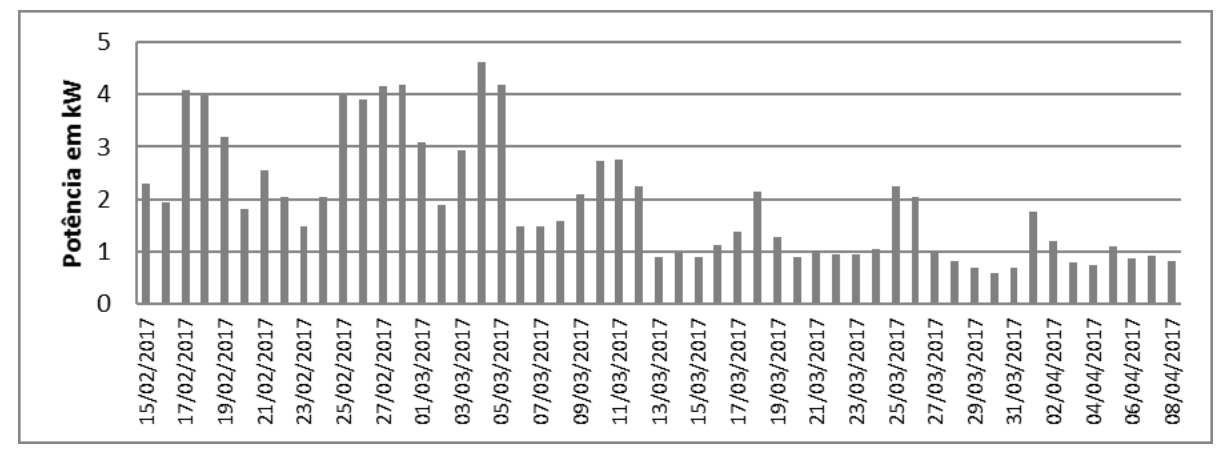

A análise do gráfico permite perceber o consumo diferenciado nos finais de semana, com queda acentuada durante os dias de semana e novo crescimento no final de semana subsequente. Os picos de consumo entre os dias 25/02 e 28/02 coincidem com os dias de Carnaval do ano de 2017, quando a ocupação da pousada foi alta, sofrendo pequeno decréscimo nos dias 01/03 ( $4^{\mathrm{a}}$ feira) e 02/03 ( $5^{\mathrm{a}}$ feira), retomando o crescimento em seguida até atingir o máximo consumo diário dentro do período analisado, que ocorreu no dia 04/03 (sábado), com média diária de 4,62 kW, atingindo o pico de $10,42 \mathrm{~kW}$ às 23 horas.

A Pousada B, localizada em Praia Grande, na Ilha do Mel, possui 30 apartamentos, todos com frigobar, secador de cabelo e TV de LCD. A construção está dividida em vários ambientes, com os apartamentos na forma de chalés distribuídos por toda a extensão do terreno. A maior construção unifica a lavanderia, cozinha, escritório, bar/restaurante, loja de conveniência e salão do café da manhã. A Figura 6 ilustra uma visão parcial da pousada B, com destaque para o telhado verde do complexo do restaurante e vista parcial dos chalés que possuem aquecimento de água com coletores solares e boilers já instalados no telhado. As possibilidades para instalação dos painéis fotovoltaicos com inclinação para o norte são inúmeras, nos telhados das várias construções.

Figura 6 - Telhado verde da pousada B com vista parcial dos chalés

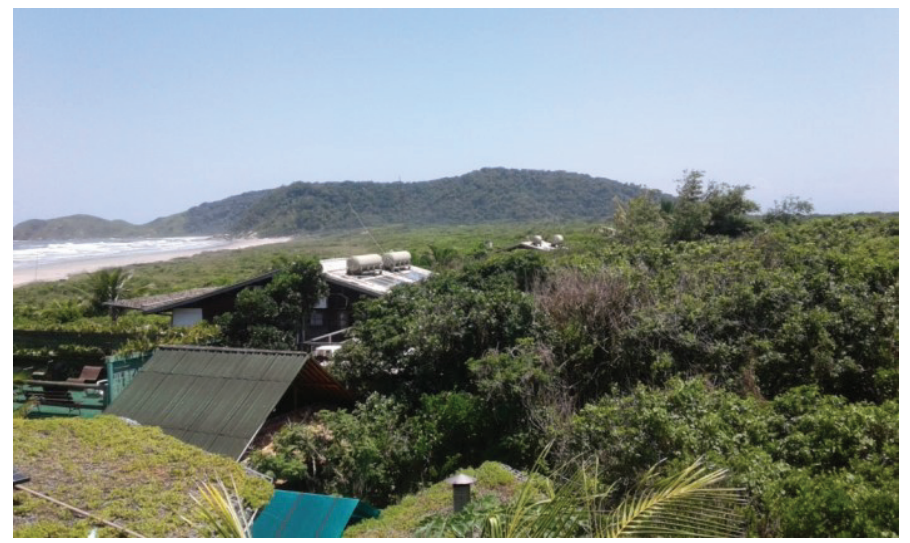


Com 15 funcionários fixos, chegando a mais de 20 na alta temporada, em função da loja de conveniência e do restaurante abertos o ano todo ao público em geral, o consumo de energia da pousada é sempre elevado. São, no total, 36 equipamentos de ar condicionado convencionais, 30 frigobares, 30 secadores de cabelo, 10 boilers (500 W) para aquecimento de água, 4 chuveiros elétricos, 4 geladeiras, 10 freezers, 2 máquinas de gelo, 1 lavadora de copos, 1 fritadeira elétrica, 1 forno elétrico, 1 balcão frigorífico, 1 micro-ondas, 2 lavadoras de roupa, 1 secadora de roupas industrial (18,55 $\mathrm{kW})$ e 6 bombas de água para garantir o armazenamento de 60 mil litros.

O consumo médio da Pousada B, entre os meses de março de 2015 e março de 2017 foi de $10015 \mathrm{kWh}$, com os maiores valores concentrados nos meses de janeiro/16 (16092 kWh) e janeiro/17 (16071 kWh) e os menores nos meses de julho/15 (5858 kWh) e julho/16 (6296 kWh). Para esta pousada, o equipamento MARH-21 ficou instalado entre os dias 12/04/17 e 27/05/17. Após o tratamento dos dados brutos com o software Excel, foi possível obter os valores da potência $(\mathrm{kW})$ para cada hora do dia para todo o período monitorado. A Figura 7 ilustra a curva de carga da Pousada B para três dias distintos, de baixa (05/mai), média (06/mai) e alta ocupação (14/abr).

Figura 7 - Curva de carga para três dias da pousada B

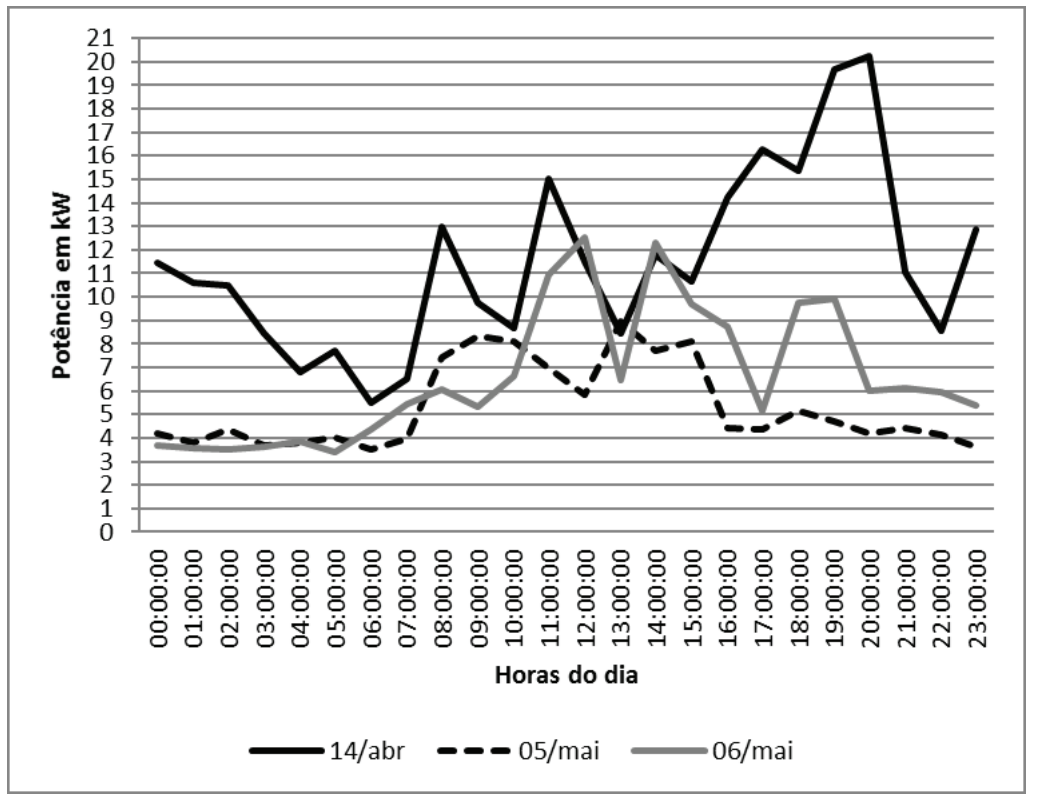

Por se tratar de uma pousada, existem diferenças significativas na curva de carga em dias muito próximos dentro do mesmo mês. A série de dados do dia 05/05 ilustra a curva de carga para cada hora, sendo que a Pousada B estava sem nenhum apartamento ocupado e sem hóspedes. Já no dia seguinte, 06/05, a ocupação era parcial, com 28 hóspedes e 11 apartamentos ocupados enquanto que no dia 14/04, sexta feira do feriado de Páscoa, a ocupação era máxima, com 67 hóspedes em 25 apartamentos. A Figura 8 ilustra a potência média por dia para todo o período de monitoramento. 
Figura 8 - Potência média diária da pousada B

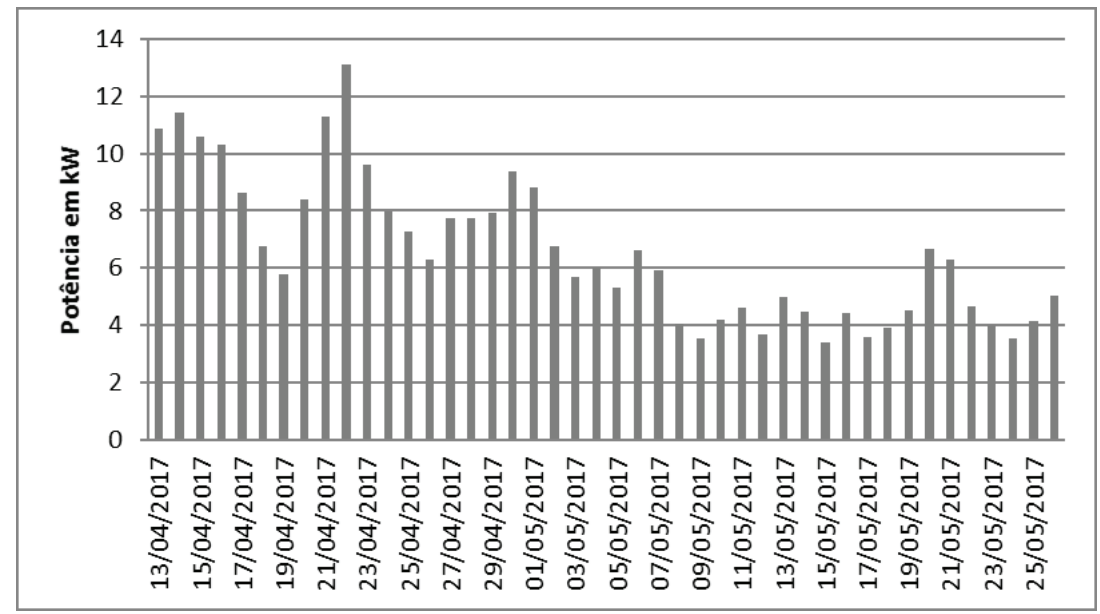

Pela análise do gráfico percebe-se o elevado consumo diário ocorrido nos feriados prolongados da Páscoa que ocorreram entre 14 e 16/04 e de Tiradentes, entre os dias 21 e 23/04. Outro pico de consumo ocorreu no feriado prolongado do dia do Trabalho, que em 2017 foi de 29/04 a 01/05. Após esses períodos constata-se baixa no consumo diário durante os dias da semana, apresentando pequenos aumentos nos finais de semana.

\subsection{Modelagem, simulação e otimização no HOMER}

Após o levantamento dos dados climáticos, da curva de carga das pousadas e da pesquisa de mercado para obtenção dos custos dos equipamentos necessários no sistema de geração de energia, foi necessário efetuar a modelagem no software HOMER antes de realizar a simulação e a otimização. Inicialmente foram inseridos no HOMER todos os dados climáticos como temperatura, velocidade do vento e radiação solar, sendo considerados constantes em todas as simulações realizadas, bem como as informações sobre carga primária, dados técnicos dos painéis, inversores e turbinas eólicas.

A entrada de dados do software referente às turbinas eólicas foi realizada com a utilização do manual técnico fornecido pelos fabricantes. Os modelos selecionados, por possuírem as características ideais para o sistema proposto na Pousada A, foram o ELV H3.8 de potência nominal igual a 2,0 kW e potência máxima de 3,2 kW; o modelo ELV H4.6 de potência nominal igual a $3,0 \mathrm{~kW}$ e potência máxima de 4,5 kW; o modelo ELV H6.4 de potência nominal igual a 5,0 kW e máxima de 7,5 kW e o modelo Skystream Marine de potência nominal igual a 2,4 kW e máxima de 2,5 kW. A Figura 9 ilustra a tela de entrada de dados referente à turbina eólica, em que o software já efetuou a construção das curvas de carga da turbina selecionada e também da curva de custo para uma quantidade máxima de duas turbinas no sistema de geração híbrido. 
Figura 9- Tela de entrada do HOMER para a turbina eólica - pousada A

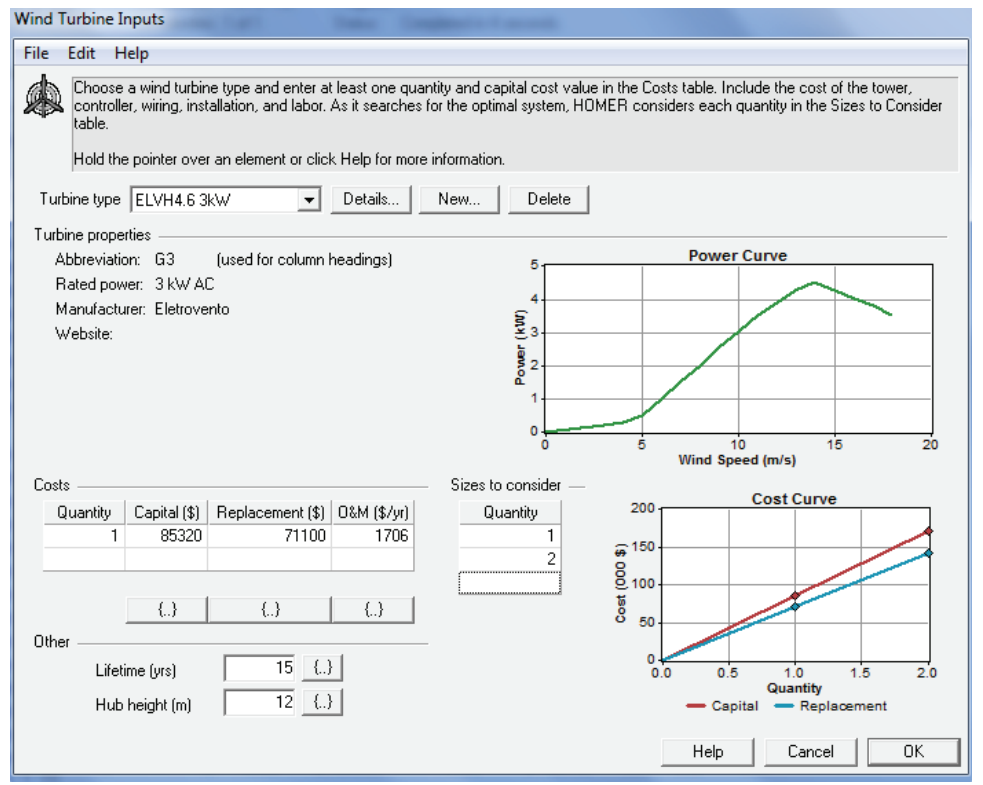

Para a confecção da modelagem do sistema híbrido de geração de energia para a Pousada $\mathrm{B}$, o procedimento foi idêntico ao relatado para a Pousada A, seguindo as mesmas premissas em relação aos dados de entrada no software para a carga primária, apenas aumentando a potência de $12 \mathrm{~kW}$ para $25 \mathrm{~kW}$ do sistema fotovoltaico em virtude do maior consumo desta pousada em relação à primeira. A Figura 10 demonstra as entradas no HOMER referente à carga primária, onde se pode observar o gráfico do perfil diário para o mês selecionado (janeiro), assim como o mapa de distribuição da demanda ao longo do ano e o perfil sazonal, onde aparecem as máximas, médias e mínimas demandas diárias durante todos os meses do ano.

Figura 10 - Tela de entrada do HOMER para a carga primária - pousada B

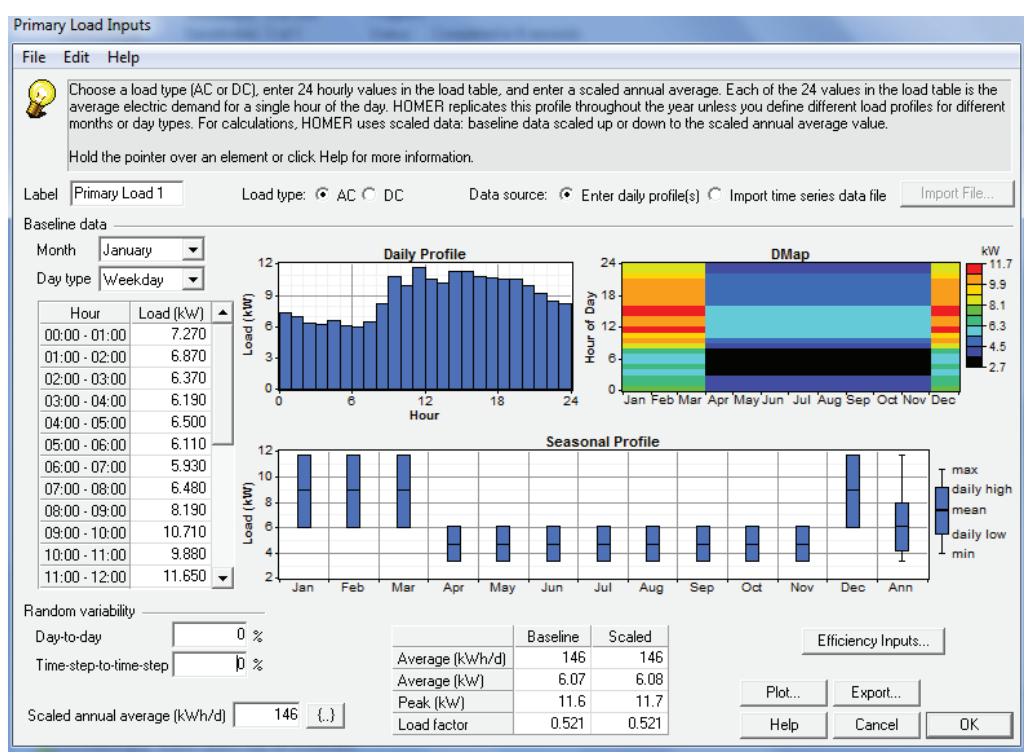


Após a etapa de modelagem do sistema no HOMER ser completada, foi efetuada a simulação com as seguintes topologias para cada pousada selecionada:

- Sistema de geração apenas com energia solar conectado à rede;

- Sistema de geração apenas com energia eólica conectado à rede;

- Sistema de geração com energia eólica e solar conectado à rede.

Ao final do processo de cálculo de todas as simulações, os resultados foram ordenados de maneira crescente, para cada topologia, em relação ao NPC - Custo Presente Líquido, que demonstra qual o custo total do sistema em todo o período de vida útil.

A primeira topologia simulada para a Pousada A incluiu apenas o sistema fotovoltaico conectado à rede elétrica da concessionária local. Com as várias opções de potências do sistema e dos conversores selecionados, o HOMER gerou 61 combinações, sendo as 46 primeiras, consideradas em relação ao NPC total do projeto, mais viáveis do que a conexão apenas com a rede elétrica da concessionária. A Tabela 3 apresenta os primeiros quinze resultados, ordenados em ordem crescente do NPC, além do resultado apenas com a rede elétrica conectada (resultado número 47).

Tabela 3 - Simulação apenas com sistema fotovoltaico na pousada A - topologia 1

\begin{tabular}{l|c|c|c|c|c}
\hline $\begin{array}{l}\text { Resultado } \\
\text { número }\end{array}$ & $\begin{array}{c}\text { Potência do sistema } \\
\text { fotovoltaico }(\mathrm{kW})\end{array}$ & $\begin{array}{c}\text { Potência do conversor } \\
(\mathrm{kW})\end{array}$ & $\begin{array}{c}\text { Capital inicial } \\
(\mathrm{R} \$)\end{array}$ & $\begin{array}{c}\text { NPC total do } \\
\text { projeto } \\
(\mathrm{R} \$)\end{array}$ & $\begin{array}{c}\text { Média do percentual } \\
\text { de produção de } \\
\text { renováveis }\end{array}$ \\
\hline 1 & 12,0 & 12 & 24.937 & 64.068 & 0,56 \\
\hline 2 & 12,0 & 10 & 25.781 & 65.174 & 0,56 \\
\hline 3 & 11,0 & 12 & 23.954 & 72.938 & 0,53 \\
\hline 4 & 11,0 & 10 & 24.798 & 74.045 & 0,53 \\
\hline 5 & 12,0 & 6 & 27.470 & 76.087 & 0,56 \\
\hline 6 & 12,0 & 5 & 24.054 & 79.450 & 0,56 \\
\hline 7 & 11,0 & 6 & 26.487 & 81.363 & 0,53 \\
\hline 8 & 10,0 & 12 & 22.970 & 81.808 & 0,50 \\
\hline 9 & 10,0 & 10 & 23.815 & 82.915 & 0,50 \\
\hline 10 & 11,0 & 5 & 23.071 & 83.335 & 0,53 \\
\hline 11 & 10,0 & 6 & 25.504 & 87.506 & 0,50 \\
\hline 12 & 10,0 & 5 & 22.088 & 87.844 & 0,50 \\
\hline 13 & 9,0 & 12 & 21.987 & 90.678 & 0,47 \\
\hline 14 & 9,0 & 10 & 22.831 & 91.785 & 0,47 \\
\hline 15 & 9,0 & 5 & 21.104 & 93.206 & 0,47 \\
\hline 47 & 0,0 & 0,0 & 00.000 & 153.485 & 0,00 \\
\hline
\end{tabular}

A primeira conclusão sobre a simulação dessa topologia é que algumas combinações obtidas, como a 2, 5, 6, 7, 10, 11, 12 e 15 são tecnicamente inviáveis, uma vez que a potência do sistema fotovoltaico supera a capacidade máxima de operação do conversor devendo, portanto, serem descartadas. Em contrapartida, em outros resultados, a potência do sistema fotovoltaico está subdimensionada em relação à potência do conversor selecionado, como ocorre, por exemplo, nos resultados 8, 13 e 14. Esse fato não inviabiliza tecnicamente o projeto, pois permite que ocorra uma expansão futura do sistema fotovoltaico, se houver disponibilidade financeira do proprietário para tal. 
Os resultados 1, 3, 4 e 9, apresentam as potências do sistema fotovoltaico mais compatíveis com o conversor selecionado. No caso do resultado 1, considerado ideal pelo software, o sistema fotovoltaico configurado com uma potência de $12,0 \mathrm{~kW}$ foi capaz de gerar uma média de 56\% da energia demandada durante um ano, sendo a produção estimada em 14.123 kWh, com um NPC de R\$ 64.068,00 e uma estimativa de compra de $3.592 \mathrm{kWh}$ de energia durante o ano. A análise econômica efetuada pelo HOMER demonstra que esse resultado é viável, quando comparado com o sistema de base escolhido que seria apenas a rede da concessionária.

O Valor Presente (Present Worth), que é a diferença entre os custos atuais líquidos do sistema apenas com a rede e do sistema simulado, ficou para o resultado $1 \mathrm{em} \mathrm{R} \$$ 89.407,00, sendo que o Valor Anual (Annual Worth), que é o Valor Presente multiplicado pelo fator de recuperação de capital, ficou em R\$ 6.344,00/ano. A taxa de Retorno do Investimento (Return On Investment) ficou em 32,6\%. O número de anos em que o fluxo de caixa descontado muda de negativo para positivo (Discounted Payback) nesta configuração, foi calculado em 3,31 anos e o custo da energia ficou em R\$ 0,267/kWh, o que significa 41,7\% do custo atual da rede. A Figura 11 mostra o gráfico da média mensal de produção elétrica para esse resultado onde se destaca a produção pelo sistema fotovoltaico praticamente constante durante o ano.

Figura 11 - Gráfico da média mensal de produção elétrica do resultado 1 na pousada A -Topologia 1

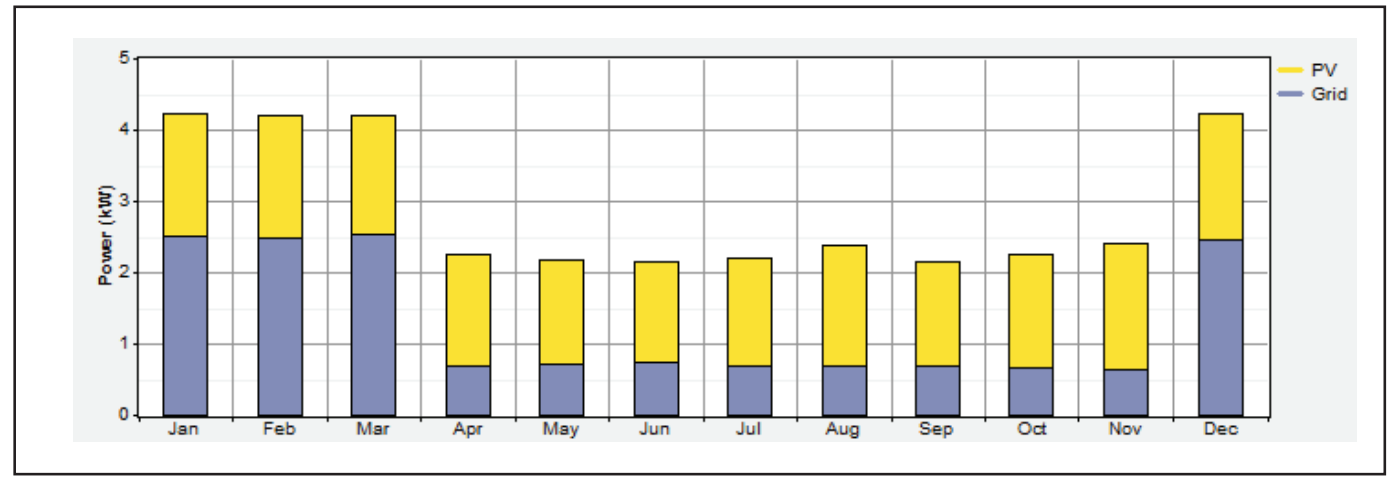

A segunda topologia simulada para a Pousada A incluiu apenas o sistema eólico conectado à rede elétrica da concessionária local. Com os quatro modelos de aerogeradores simulados (de 2, 2.4, 3 e $5 \mathrm{~kW}$ ), o software apresentou oito combinações distintas, realizando apenas combinações com modelos de mesma potência, que são explicitadas na Tabela 4, por ordem crescente de NPC.

Tabela 4 - Simulação apenas com sistema eólico na pousada A - topologia 2

\begin{tabular}{c|c|c|c|c|c|c}
\hline $\begin{array}{c}\text { Resultado } \\
\text { número }\end{array}$ & $\begin{array}{c}\text { Potência do } \\
\text { sistema eólico } \\
(\mathrm{kW})\end{array}$ & $\begin{array}{c}\text { Número } \\
\text { de } \\
\text { turbinas }\end{array}$ & $\begin{array}{c}\text { Capital inicial } \\
(\mathrm{R} \$)\end{array}$ & $\begin{array}{c}\text { NPC total do } \\
\text { projeto } \\
(\mathrm{R} \$)\end{array}$ & $\begin{array}{c}\text { Média do percentual } \\
\text { de produção de } \\
\text { renováveis }\end{array}$ & $\begin{array}{c}\text { Crédito anual } \\
\text { de energia } \\
(\mathrm{kWh})\end{array}$ \\
\hline 1 & 0,0 & 0 & 00.000 & 153.485 & 0,00 \\
\hline 2 & 2,4 & 1 & 55.200 & 215.809 & 0,14 \\
\hline 3 & 2,0 & 1 & 59.820 & 222.260 & 0,15 \\
\hline 4 & 3,0 & 1 & 85.320 & 250.954 & -14.556 \\
\hline 5 & 5,0 & 1 & 108.900 & 275.394 & -14.488 \\
\hline 6 & 4,8 & 2 & 110.400 & 278.143 & 0,28 & 0,28 \\
\hline 7 & 4,0 & 2 & 119.640 & 291.046 & -13.344 \\
\hline 8 & 6,0 & 2 & 170.640 & 348.434 & -12.054 \\
\hline 9 & 10,0 & 2 & 217.800 & 397.313 & -12.103 \\
\hline & & & & & -11.967 \\
\hline
\end{tabular}


A primeira conclusão que se obtém da simulação dessa topologia é que em todos os resultados obtidos, independentemente do número de aerogeradores e da potência dos mesmos, o valor obtido no NPC total do projeto supera no mínimo $40 \%$ o valor obtido apenas com a utilização da rede da concessionária. Em nenhum dos casos simulados existe excedente anual de energia. Para o resultado número 9, onde o sistema eólico possui dois geradores ELV de 5 kW, a produção estimada de energia renovável ficou em $9.911 \mathrm{kWh} /$ ano representando em média 48,4\% do total da demanda anual.

Os dados econômicos para esse resultado apresentam um custo de energia de $\mathrm{R} \$ 1,657 / \mathrm{kWh}$, o que supera em 158,9\% o valor atual da concessionária. O Valor Presente ficou em - R\$243.838,00, o Valor Anual em - R\$ 17.301,00/ano com um Retorno do Investimento negativo.

Por problemas de limitação do software HOMER com relação ao número de aerogeradores, a terceira topologia para a Pousada A, que inclui o sistema de geração de energia distribuída composto por painéis fotovoltaicos e turbinas eólicas, foi simulada em quatro etapas distintas sendo:

I. Painéis fotovoltaicos e 1 ou 2 aerogeradores de $2,0 \mathrm{~kW}$;

II. Painéis fotovoltaicos e 1 ou 2 aerogeradores de $2,4 \mathrm{~kW}$;

III. Painéis fotovoltaicos e 1 ou 2 aerogeradores de $3,0 \mathrm{~kW}$;

IV. Painéis fotovoltaicos e 1 ou 2 aerogeradores de $5,0 \mathrm{~kW}$.

A Tabela 5 apresenta um resumo da terceira topologia simulada, onde aparecem o melhor resultado de cada etapa bem como o primeiro com dois aerogeradores de cada modelo selecionado.

Tabela 5 - Simulação com sistema fotovoltaico e eólico na pousada A - topologia 3

\begin{tabular}{|c|c|c|c|c|c|c|}
\hline $\begin{array}{l}\text { Resultado } \\
\text { número }\end{array}$ & $\begin{array}{c}\text { Potência do } \\
\text { sistema } \\
\text { fotovoltaico }(\mathrm{kW}) \\
\end{array}$ & $\begin{array}{c}\text { Potência do } \\
\text { sistema eólico } \\
(\mathrm{kW}) \\
\end{array}$ & $\begin{array}{c}\text { Potência do } \\
\text { conversor }(\mathrm{kW})\end{array}$ & $\begin{array}{c}\text { Capital } \\
\text { inicial } \\
(\mathrm{R} \$) \\
\end{array}$ & $\begin{array}{l}\text { NPC total do } \\
\text { projeto } \\
(\mathrm{RS}) \\
\end{array}$ & $\begin{array}{l}\text { Média do percentual de } \\
\text { produção de renováveis }\end{array}$ \\
\hline \multicolumn{7}{|l|}{ Etapa 1} \\
\hline 1 & 12,0 & 2,0 & 12,0 & 82.896 & 127.834 & 0,62 \\
\hline 37 & 11,0 & 4,0 & 12,0 & 141.733 & 208.720 & 0,66 \\
\hline \multicolumn{7}{|l|}{ Etapa 2} \\
\hline 1 & 12,0 & 2,4 & 12,0 & 78.276 & 124.542 & 0,63 \\
\hline 39 & 12,0 & 4,8 & 12,0 & 133.476 & 198.732 & 0,68 \\
\hline \multicolumn{7}{|l|}{ Etapa 3} \\
\hline 1 & 12,0 & 3,0 & 12,0 & 110.257 & 162.203 & 0,65 \\
\hline 73 & 12,0 & 6,0 & 12,0 & 195.577 & 292.751 & 0,73 \\
\hline \multicolumn{7}{|l|}{ Etapa 4} \\
\hline 1 & 11,0 & 5,0 & 12,0 & 130.993 & 195.211 & 0,66 \\
\hline 85 & 12,0 & 10,0 & 12,0 & 240.876 & 363.064 & 0,76 \\
\hline
\end{tabular}

Dentre todos os resultados viáveis, o 1 da etapa I é o que apresenta menor NPC e maior média do percentual de energia renovável, com $62 \%$, dos quais 53\% produzidos pelo sistema fotovoltaico e $9 \%$ pela turbina eólica de $2 \mathrm{~kW}$. Para este resultado, o custo de energia ficou em $\mathrm{R} \$ 0,533 / \mathrm{kWh}$, o que representa $83,3 \%$ do custo da rede da concessionária. O Valor 
Presente foi calculado em $\mathrm{R} \$ 25.641,00$, o Valor Anual em $\mathrm{R} \$ 1.819,00 /$ ano, com uma taxa de Retorno de Investimento de 9,32\% e um Payback de 12,1 anos. A Figura 12 ilustra a média mensal de produção elétrica para este resultado específico, onde se percebe a elevada produção do sistema fotovoltaico. Para este resultado, ainda não existe sobra de energia anual, devendo ser comprada da rede $1.071 \mathrm{kWh} / \mathrm{ano}$. Apenas no resultado 37, com duas turbinas, existe a sobra estimada de 332 kWh/ano, mas o investimento inicial fica em R\$ 141.733,00 e o NPC total do projeto sobe para R\$208.720,00.

\section{Figura 12 - Gráfico da média mensal de produção elétrica do resultado 1 - Topologia 3 - etapa I}

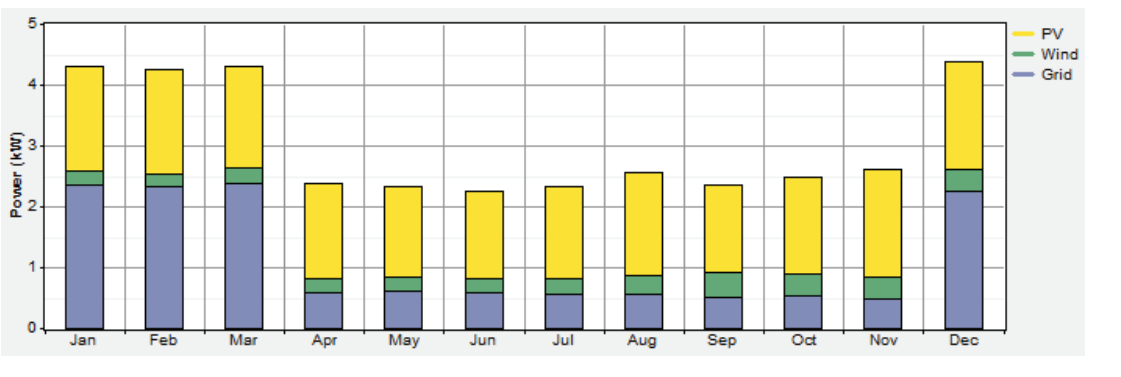

Para a Pousada B, optou-se por demonstrar neste trabalho apenas a simulação da terceira topologia, que inclui o sistema eólico juntamente com o fotovoltaico conectados à rede. O HOMER produziu 200 resultados de possíveis combinações, sendo que os primeiros 26 apresentados possuem apenas uma única turbina eólica modelo ELV de 5,0 kW com várias combinações de sistemas fotovoltaicos. A Tabela 6 apresenta os primeiros quinze resultados, ordenados em ordem crescente do NPC para esta etapa além do resultado 27 que apresenta a maior porcentagem de geração de energia com as fontes renováveis utilizando dois aerogeradores.

Tabela 6 - Simulação com sistema fotovoltaico e eólico $(5,0 \mathrm{~kW}$ ou $10,0 \mathrm{~kW})$ na pousada $\mathrm{B}$ - Topologia

\begin{tabular}{|c|c|c|c|c|c|c|}
\hline $\begin{array}{l}\text { Resultado } \\
\text { número }\end{array}$ & $\begin{array}{l}\text { Potência do sistema } \\
\text { fotovoltaico }(\mathrm{kW})\end{array}$ & $\begin{array}{c}\text { Potência do } \\
\text { sistema eólico } \\
(\mathbf{k W})\end{array}$ & $\begin{array}{c}\text { Potência do } \\
\text { conversor }(\mathbf{k W})\end{array}$ & $\begin{array}{c}\text { Capital } \\
\text { inicial } \\
(\mathbf{R} \$)\end{array}$ & $\begin{array}{l}\text { NPC total } \\
\text { do projeto } \\
\text { (RS) }\end{array}$ & $\begin{array}{l}\text { Média do } \\
\text { percentual de } \\
\text { produção de } \\
\text { renováveis }\end{array}$ \\
\hline 1 & 25,0 & 5,0 & 25,0 & 154.648 & 409.872 & 0,53 \\
\hline 2 & 25,0 & 5,0 & 20,0 & 157.432 & 413.714 & 0,53 \\
\hline 3 & 25,0 & 5,0 & 15,0 & 155.032 & 416.317 & 0,53 \\
\hline 4 & 25,0 & 5,0 & 12,0 & 149.291 & 423.955 & 0,53 \\
\hline 5 & 25,0 & 5,0 & 10,0 & 145.464 & 435.710 & 0,53 \\
\hline 6 & 20,0 & 5,0 & 12,0 & 144.374 & 451.534 & 0,47 \\
\hline 7 & 20,0 & 5,0 & 25,0 & 149.731 & 454.223 & 0,47 \\
\hline 8 & 20,0 & 5,0 & 15,0 & 150.115 & 454.864 & 0,47 \\
\hline 9 & 20,0 & 5,0 & 10,0 & 140,547 & 455.982 & 0,47 \\
\hline 10 & 20,0 & 5,0 & 20,0 & 152.515 & 458.058 & 0,47 \\
\hline 11 & 15,0 & 5,0 & 10,0 & 135.630 & 487.005 & 0,40 \\
\hline 12 & 25,0 & 5,0 & 6,0 & 146.872 & 491,083 & 0,51 \\
\hline 13 & 15,0 & 5,0 & 12,0 & 139.458 & 491.136 & 0,40 \\
\hline 14 & 20,0 & 5,0 & 6,0 & 141.955 & 498.099 & 0,46 \\
\hline 15 & 15,0 & 5,0 & 25,0 & 144.814 & 498.574 & 0,40 \\
\hline 27 & 25,0 & 10,0 & 25,0 & 263.548 & 531.791 & 0,59 \\
\hline
\end{tabular}


Para o resultado número 1 , o percentual de energia produzida utilizando as fontes renováveis atinge 53\%, sendo que $45 \%$ é proveniente do sistema fotovoltaico e apenas $9 \%$ do sistema eólico com uma única turbina de 5,0 kW. Para este resultado, ainda é necessário adquirir $20.381 \mathrm{kWh}$ durante o ano, pois a produção do sistema fotovoltaico estimada anualmente é de $29.423 \mathrm{kWh}$ enquanto a do sistema eólico chega a $4.956 \mathrm{kWh}$. O custo de energia ficou em R\$ 0,546/kWh, o que representa $85,3 \%$ do custo da rede da concessionária. O Valor Presente foi calculado em R\$ 70.954,00, o Valor Anual em R\$ 5.034,00/ano, com uma taxa de Retorno de Investimento de 10,4\% e um Payback de 10,7 anos. A Figura 13 ilustra a produção solar e eólica para esse resultado, onde se percebe a produção solar praticamente constante durante todo o ano, bem como a baixa produção eólica.

Figura 13 - Gráfico da média mensal de produção elétrica do resultado 1 - Topologia 3 - pousada B

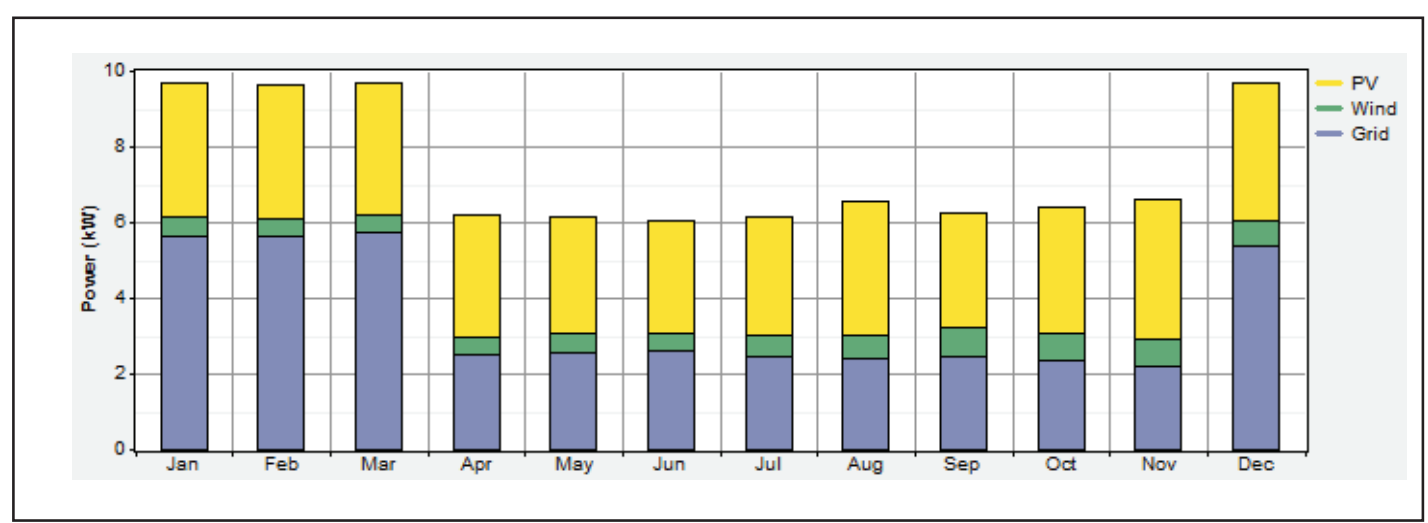

$\mathrm{Na}$ etapa de análise de sensibilidade, variáveis como velocidade do vento, irradiação solar e temperatura foram mantidas constantes, uma vez que são baseadas em séries históricas de 30 anos e dificilmente sofrerão grandes variações. As variáveis selecionadas para essa análise foram a taxa de inflação, o tempo de vida útil e os custos de reposição dos componentes do sistema.

A análise de sensibilidade para este trabalho seguirá as seguintes premissas:

1. Redução da taxa de juros real anual de $5 \%$ para $4 \%$, provocada por uma estimativa de redução da taxa de juros anual para empréstimo em $20 \%$;

2. Redução de $59 \%$ do valor de reposição dos componentes que constituem o sistema fotovoltaico;

3. Redução de $35 \%$ do valor de reposição dos componentes que constituem o sistema eólico;

4. Aumento da vida útil dos componentes do sistema fotovoltaico para 20 ou até 25 anos;

5. Aumento da vida útil dos componentes do sistema eólico para 20 ou até 25 anos.

Para a Pousada A, a análise de sensibilidade foi realizada utilizando a terceira topologia simulada, etapa IV. Nesta simulação, o melhor resultado era composto de um sistema fotovoltaico de $11,0 \mathrm{~kW}$, conversor de $12,0 \mathrm{~kW}$ com um aerogerador de 5,0 kW. Neste caso o investimento inicial, que não sofrerá alteração na análise de sensibilidade ficou em R\$ 130.993,00, com um NPC total de R\$ 195.211,00. A Tabela 7 ilustra algumas das combinações da análise de sensibilidade para esta topologia da Pousada A. 
Tabela 7 - Análise de sensibilidade - pousada A - topologia 3

\begin{tabular}{|c|c|c|c|c|c|c|c|}
\hline $\mathbf{N}^{0}$ & $\begin{array}{l}\text { Vida útil do } \\
\text { Conversor } \\
\quad(\text { anos })\end{array}$ & $\begin{array}{l}\text { Vida útil da } \\
\text { Turbina } \\
\text { (anos) }\end{array}$ & $\begin{array}{l}\text { Taxa de } \\
\text { Juros real } \\
\text { anual } \\
(\%)\end{array}$ & $\begin{array}{l}\text { Percentual de } \\
\text { redução do valor de } \\
\text { reposição dos } \\
\text { componentes solares }\end{array}$ & $\begin{array}{l}\text { Percentual de } \\
\text { redução do valor de } \\
\text { reposição dos } \\
\text { componentes } \\
\text { eólicos } \\
\end{array}$ & $\begin{array}{c}\text { Custo de } \\
\text { Operação } \\
\text { (R\$/ano) }\end{array}$ & $\begin{array}{l}\text { NPC Total } \\
\text { (R\$) }\end{array}$ \\
\hline 1 & 15 & 15 & 5 & 0 & 0 & 4.556 & 195.211 \\
\hline 2 & 20 & 15 & 5 & 0 & 0 & 4.406 & 193.098 \\
\hline 3 & 25 & 15 & 5 & 0 & 0 & 4.304 & 191.652 \\
\hline 4 & 15 & 20 & 5 & 0 & 0 & 3.094 & 174.595 \\
\hline 5 & 20 & 20 & 5 & 0 & 0 & 2.944 & 172.482 \\
\hline 6 & 15 & 20 & 4 & 59 & 35 & 2.607 & 171.712 \\
\hline 7 & 20 & 20 & 4 & 59 & 35 & 2.544 & 170.739 \\
\hline 8 & 15 & 25 & 5 & 0 & 0 & 2.093 & 160.492 \\
\hline 9 & 25 & 25 & 4 & 59 & 35 & 1.841 & 156.933 \\
\hline
\end{tabular}

Mesmo na melhor das situações, da análise de sensibilidade que é a $\mathrm{n}^{\circ} 9$, onde se pressupõe que a vida útil do conversor e da turbina eólica sejam a mesma de todo o sistema, eliminando substituições de componentes, o NPC total do projeto ficou em R\$ 156.933,00, com um Valor Presente de - R\$ 3.458,00, pois o NPC apenas com a utilização da rede elétrica da distribuidora foi calculado em R\$ 153.475,00. Neste item, o Valor Anual ficou em - R\$ 245,00 e um Payback que não pode ser calculado, pois o investimento não se paga durante o tempo de vida estimado do projeto. Dessa forma, o sistema simulado na terceira topologia, etapa IV, não deve ser utilizado na Pousada A por razões exclusivamente econômicas.

Para a Pousada B, a análise de sensibilidade também foi realizada utilizando a terceira topologia simulada, com aerogerador de potência igual a 5,0 kW. Nesta simulação, o melhor resultado era composto de um sistema fotovoltaico de $25,0 \mathrm{~kW}$, conversor de 25,0 kW com um aerogerador de 5,0 kW. Neste caso o investimento inicial, que não sofrerá alteração na análise de sensibilidade, ficou em R\$ 154.648,00, com um NPC total de R \$409.872,00. A Tabela 8 ilustra algumas das combinações da análise de sensibilidade para esta topologia da Pousada B.

Tabela 8 - Análise de sensibilidade - pousada B - topologia 3

\begin{tabular}{|c|c|c|c|c|c|c|c|}
\hline $\mathbf{N}^{o}$ & $\begin{array}{l}\text { Vida útil do } \\
\text { Conversor } \\
\text { (anos) }\end{array}$ & $\begin{array}{l}\text { Vida útil da } \\
\text { Turbina } \\
\text { (anos) }\end{array}$ & $\begin{array}{c}\text { Taxa de } \\
\text { Juros real } \\
\text { anual } \\
(\%)\end{array}$ & $\begin{array}{l}\text { Percentual de } \\
\text { redução do valor de } \\
\text { reposição dos } \\
\text { componentes solares }\end{array}$ & $\begin{array}{l}\text { Percentual de } \\
\text { redução do valor de } \\
\text { reposição dos } \\
\text { componentes } \\
\text { eólicos }\end{array}$ & $\begin{array}{c}\text { Custo de } \\
\text { Operação } \\
\text { (R\$/ano) }\end{array}$ & $\begin{array}{l}\text { NPC Total } \\
\text { (R\$) }\end{array}$ \\
\hline 1 & 15 & 15 & 5 & 0 & 0 & 18.109 & 409.872 \\
\hline 2 & 15 & 20 & 4 & 0 & 35 & 16.314 & 409.505 \\
\hline 3 & 15 & 15 & 5 & 0 & 35 & 17.801 & 405.540 \\
\hline 4 & 20 & 15 & 5 & 59 & 0 & 17.675 & 403.753 \\
\hline 5 & 25 & 20 & 4 & 0 & 35 & 15.785 & 401.249 \\
\hline 6 & 15 & 15 & 5 & 59 & 35 & 16.939 & 393.389 \\
\hline 7 & 25 & 25 & 4 & 59 & 0 & 15.124 & 390.923 \\
\hline 8 & 20 & 25 & 5 & 0 & 0 & 15.336 & 370.793 \\
\hline 9 & 25 & 25 & 5 & 0 & 35 & 15.124 & 367.811 \\
\hline
\end{tabular}


A melhor condição da análise de sensibilidade é a n ${ }^{\circ}$, onde se pressupõe que a vida útil do conversor e da turbina eólica sejam a mesma de todo o sistema, eliminando substituições de componentes, o NPC total do projeto ficou em R\$ 367.811,00, com um Valor Presente de R \$113.015,00, pois o NPC apenas com a utilização da rede elétrica da distribuidora foi calculado em R $\$ 480.825,00$. Neste item, o Valor Anual ficou em R \$ 8.019,00, a Taxa de Retorno do Investimento ficou em 12,3\% e o Payback descontado em 10,7 anos. A Figura 14 ilustra o gráfico do fluxo de caixa acumulado em função dos anos do projeto, referente ao item 9 da análise de sensibilidade da Pousada B, comparando a rede da concessionária e o sistema em análise. Dessa forma, o sistema simulado na terceira topologia, etapa IV, é altamente recomendado para a Pousada B, por razões técnicas e econômicas.

Figura 14 - Gráfico do fluxo de caixa acumulado - pousada B

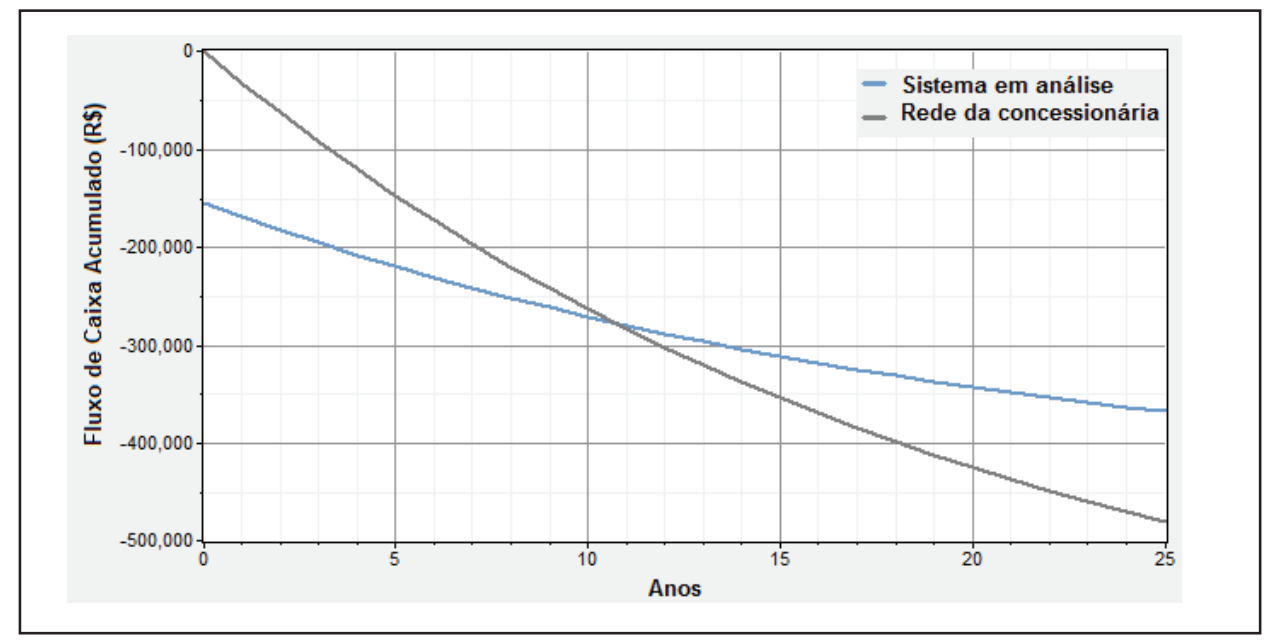

Para cada sistema simulado, em ambas as pousadas, é possível efetuar a análise de sensibilidade com a inserção de faixas de valores para as variáveis escolhidas e analisar a influência de cada variável de sensibilidade no sistema que foi simulado. Sistemas que apresentavam uma situação de alguma inviabilidade podem, após essa etapa se tornarem viáveis tanto econômica quanto tecnicamente sendo passíveis de execução, mas, a situação contrária também é verdadeira, tornando a análise desta etapa muito mais complexa.

\section{Conclusões}

Com as várias topologias modeladas e simuladas em cada estabelecimento foi possível propor a implantação de sistemas de produção de energia distribuída com base nos dados da demanda, além de verificar o custo/benefício de cada um desses sistemas híbridos de geração de energia, fazendo uso do software HOMER e posteriormente realizar a análise de sensibilidade dos sistemas.

Aliando o favorecimento da legislação com o aproveitamento de recursos naturais do litoral paranaense, com radiação solar média diária de $4,0 \mathrm{kWh} / \mathrm{m}^{2}$, ventos com média anual de $3,5 \mathrm{~m} / \mathrm{s}$ e temperatura do ar em $20,7^{\circ} \mathrm{C}$, foi possível propor a utilização de um sistema de geração híbrido eólico/solar de geração de energia distribuída em estabelecimentos comerciais na Ilha do Mel - PR.

Após realizar as simulações com diversas topologias de geração distribuída para as Pousadas A e B, foram encontrados vários arranjos viáveis tanto do ponto de vista técnico quanto econômico. De maneira geral, para ambas as 
pousadas, sistemas de geração envolvendo apenas energia eólica, são inviáveis economicamente, pois em todas as simulações realizadas, o NPC dos sistemas foi superior ao da utilização apenas com a rede da concessionária. Em ambas as pousadas, sistemas de geração apenas com energia solar, mostraram-se sempre viáveis técnica e economicamente, apesar de em nenhum caso os sistemas suprirem a demanda anual de energia dos estabelecimentos.

Para a Pousada A, que possui 10 apartamentos e uma média de consumo de 1195,75 kWh/mês, o sistema híbrido eólico/solar com menor NPC total do projeto, viável técnica e economicamente, foi composto de um sistema fotovoltaico de $12,0 \mathrm{~kW}$, um conversor de 12,0 kW e uma única turbina eólica de 2,4 kW. Nesta melhor configuração, a média de produção de energia usando fontes renováveis atingiu $62,5 \%$ da demanda, sendo $53,5 \%$ produzida pelo sistema fotovoltaico e apenas $9 \%$ pela turbina eólica. Para este resultado, o custo de energia ficou em R $\$ 0,520 / \mathrm{kWh}$, o que representa $81,3 \%$ do custo da rede da concessionária. O Valor Presente foi calculado em R \$28.933,00, o Valor Anual em R \$2.053,00/ano, com uma taxa de Retorno de Investimento de 9,75\% e um Payback de 11,5 anos, indicadores atrativos para a instalação do sistema.

Para a Pousada B, que conta com 30 apartamentos e possui uma média de consumo de $10.015 \mathrm{kWh} / \mathrm{mês}$, o sistema híbrido eólico/solar com menor NPC total do projeto, viável técnica e economicamente, foi composto de um sistema fotovoltaico de 25,0 kW, um conversor de 25,0 kW e uma única turbina eólica de 5,0 kW. Nesta configuração, a média de produção de energia usando fontes renováveis atingiu $53,0 \%$ da demanda, sendo $45,0 \%$ produzida pelo sistema fotovoltaico e 9\% pela turbina eólica. Para este resultado, ainda será necessário adquirir 20.381 kWh durante o ano, pois a produção do sistema fotovoltaico estimada anualmente será de $29.423 \mathrm{kWh}$ enquanto a do sistema eólico chega a $4.956 \mathrm{kWh}$. O custo de energia ficou em $\mathrm{R} \$ 0,546 / \mathrm{kWh}$, o que representa $85,3 \%$ do custo da rede da concessionária. O Valor Presente foi calculado em R \$ 70.954,00, o Valor Anual em R \$ 5.034,00/ano, com uma taxa de Retorno de Investimento de 10,4\% e um Payback de 10,7 anos, fatores que favorecem a instalação do sistema.

Nenhuma tentativa de aumentar a produção do sistema eólico em ambas as pousadas, colocando dois aerogeradores, se mostrou viável economicamente. A razão está no custo para aquisição ser elevado em qualquer modelo de turbina e também em função do gasto com a reposição, estimada para ocorrer no ano quinze do projeto. A análise de sensibilidade efetuada demonstrou que com a possibilidade de aumento no tempo de vida útil dos componentes do sistema, com a queda nas taxas de inflação e do custo de manutenção, outros sistemas analisados podem se tornar viáveis tanto técnica quanto economicamente.

\section{References}

ANEEL. Resolução Normativa nº 482 de 17 de Abril de 2012. Diário Ofícial da União. 2012.

ANEEL. Resolução Normativa nº 687 de 24 de Novembro de 2015. Diário Oficial da União. 2015.

ANEEL. Cadernos Temáticos - Micro e minigeração distribuída: sistema de compensação de energia elétrica. ANEEL. $2^{a}$ Edição. Brasília. 2016.

ANEEL. Acesso ao Sistema de Distribuição. Procedimentos de Distribuição de Energia Elétrica no Sistema Elétrico Nacional - PRODIST, n. Módulo 8, 2016.

ANEEL. Nota Técnica nº 0065 de 24 de Maio de 2017. Diário Oficial da União. 2017.

BARBOSA. C. F. O. Avaliação Tecnológica. Operacional e de Gestão de Sistemas Híbridos para Geração de Eletricidade na Região Amazônica [dissertation]. Programa de Pós Graduação em Engenharia Elétrica da UFPA. Belém. 2006. 
BARRETO. E. J. F. Sistemas Híbridos - soluções energéticas para a Amazônia. Ministério das Minas e Energia. $1^{a}$ Edição. Brasília. 2008.

CAMPOS, E. et al. Meta da Inflação é fixada em 4,25\% para 2019 e em 4\% para 2020 [Internet]. Valor Econômico, Brasília, Junho 2017. [cited 2017 sep 02]. Available from: http://www.valor.com.br/financas/5020956/meta-de-inflacao-efixada-em-425-para-2019-e-em-4-para-2020.

COPEL. NTC 905200 - Manual de acesso de geração distribuída ao sistema da COPEL. Normas Técnicas COPEL. 2014.

COSTA. R. R. M; Microgeração em meio urbano: um estudo de caso na cidade de Curitiba [dissertation]. Programa de Mestrado em Desenvolvimento de Tecnologia. Institutos de Tecnologia para o Desenvolvimento. Curitiba. 2014.

DUTRA. R. (Org.). Energia Eólica - princípios e tecnologias [Internet]. CRESESB. 2008. [cited 2017 jan 02]. Available from: http://www.cresesb.cepel.br/download/tutorial/tutorial_eolica_2008_e-book.pdf.

EPE. Balanço energético nacional 2018 [Internet]. Brasília. DF. 2018. [cited 2018 jul 15]. Available from: http://www.epe.gov.br/sites-pt/publicacoes-dados-abertos/publicacoes/PublicacoesArquivos/publicacao-303/topico397/Relat\%C3\%B3rio\%20S\%C3\%ADntese\%202018-ab\%202017vff.pdf.

EPE. Plano Decenal de Expansão de Energia 2024. Brasília. DF. 2015b.

ERSHAD. A. M.; BRECHA. R.; HALLINAN. K. Anallysis of solar photovoltaic and wind power potencial in Afghanistan. Renewable Energy. 2015.

FERREIRA. A. A. A. Sistema de produção de energia eólica [dissertation]. Programa de Mestrado Integrado em Engenharia Electrotécnica e de Computadores da Universidade do Porto. Porto. 2011.

HOMER ENERGY LLC. Homer Energy. [S.1: s.n.]. [cited 2017 sep 5]. Available from: http://homerenergy.com.

IRENA. A Path to Prosperity: Renewable Energy for Islands. $2^{\text {a }}$ edição. 2015.

IRENA. The Power to Change: Solar and Wind Cost Reduction Potential to 2025 [Internet]. 2016. [cited 2017 oct 10]. Available from: www.irena.org/publications.

JOHNSON. G. L. Wind Enegy Systems. Edição Eletrônica. Ed. Manhattan. KS: [s.n.]. 2006.

NREL. Best Practices in Photovoltaic System Operation and Maintenance. $2^{\text {nd }}$ Edition. 2016.

RETSCREEN Software. [cited 2017 oct 15]. Available from: http://www.nrcan.gc.ca/energy/software-tools/7465.

VILLALVA. M.G.; Energia solar fotovoltaica: conceitos e aplicações. 2a Edição. São Paulo: Érica. 2015. 